\title{
Are artificial satellites orbits influenced by an expanding Earth?
}

\author{
Giancarlo Scalera \\ Istituto Nazionale di Geofisica e Vulcanologia, Roma, Italy
}

\begin{abstract}
The possible role played by parameters linked to the expanding Earth on the effects we observe in the orbital motion of the artificial satellites is discussed here. The important result in this short note is the discrimination between the reality of the glacial rebound process and/or the relaxation of the $100 \mathrm{~m}$ excess of equatorial bulge testified by the high rate of $\dot{J}_{2}$, and the improbable role that glacial rebound can have in driving PM and TPW. It is recommended that the new technology of drag-free satellites be used (Gravity-Probe B is the first step) to reveal possible residual orbital parameter variations ascribable to formerly unrecognized fictitious drag terms due to Earth radial increase.
\end{abstract}

Key words $\mathrm{M}$ and $\mathrm{G}$ time-variations - satellite geodesy - orbit perturbations - expanding Earth

\section{Introduction}

For many years unequivocal evidence has accumulated in favour of an expanding Earth (Scalera, 1993a,b, 1994, 1997, 1998, 2001, 2002, 2003c, 2006). I have tried to test this promising new global tectonics scenario, and in particular the branch that envisages the possibility that Earth expansion is directly linked to still unknown properties of the gravitational field - an old idea with roots in the works of Yarkovsky (1888), Beekman (2006) and Hilgenberg (1929, 1931, 1933), but with more ancient background in the mechanical explanation of gravity due to Georges-Louis Le Sage (1724-1803) (Edwards, 2002).

A first significant result has been the possibility to link the actual Polar Motion (PM) to the expected - and observed - extrusion of new

Mailing address: Dr. Giancarlo Scalera, Istituto Nazionale di Geofisica e Vulcanologia, Via di Vigna Murata 605, 00143 Roma, Italy; e-mail: scalera@ingv.it crust with maximum rate in the Nazca triple point (Scalera, 2002, 2003a,c, 2006). A second result has been to become aware that many geophysical, geodetic and geological data and reasoning lead to the possibility that the Earth's local gravity can increase through geological time (Scalera, 2003b).

In this short paper my purpose is to discuss the possibility that the anomalies detected in the orbits of the artificial satellites could be linked not only to the mechanical causes of the Earth's shape variations - namely tidal deceleration and glacial isostatic rebound - but can be caused by other ongoing terrestrial physical processes, which are customarily neglected, but which can also play a role in explaining fine details in the detected secular trend of the involved observational quantities.

\section{Neglected quantities in the $J_{2}$ variation estimations}

Let us examine the further possibility that the observed anomalous higher value of $J_{2}$ variation could be a still unrecognized combination of gradients of different quantities. Initially, it can be recalled that the $J_{2}$ variation is usually detected 
from the precession of the artificial satellites' orbits. If an equatorial bulge is present, the satellites experience a perturbing force that acts trying to transform the orbits to equatorial ones. But the reaction of the orbit is to precess and a retrogradation of the ascending node is observed. The retrogradation rate is not constant but because the Earth is moving toward a more spherical shape (due at least to the tidal deceleration and glacial rebound), the distance between two successive nodes is a series of values converging to zero - in the limit of a perfect spherical Earth and without considering the apparent drift of the node due to the tidal slowing down of the Earth and all the other Earth spin irregularities.

Measuring this deceleration of the node, $\ddot{\Omega}$, it is possible to evaluate $\dot{J}_{2}$ using the following formula (Kaula, 1966; Caputo, 1967), neglecting higher order small terms and recalling that $J_{l}=$ $=-\sqrt{2 l+1} \cdot C_{l 0}$ (with $C_{l 0}$ the harmonic expansion coefficients)

$$
\frac{\partial \Omega}{\partial t}=\dot{\Omega}=-\frac{3 \cos I \cdot N_{0}}{2\left(1-e^{2}\right)^{2}}\left(\frac{R}{a_{s}}\right)^{2} J_{2}
$$

with $N_{0} \equiv \frac{2 \pi}{T}=\sqrt{\frac{G M}{a_{s}^{3}}}$

and $a_{s}=$ satellite's semimajor axis; $e=$ orbit eccentricity; $I=$ orbit inclination; $N_{0}=$ mean motion; $R=$ $=$ Earth radius. With the value of $I=109.9^{\circ}$ for Lageos the node velocity is greater than zero and directed eastward. In this first order approximation the satellite's semimajor axis is assumed constant and in the following considerations its variations will be assumed as caused only by the several types of drag affecting the satellites' orbits.

If we define

$$
P=-\frac{2\left(1-e^{2}\right)^{2}}{3 \cos I} \text {, and } K=G^{-\frac{1}{2}} \cdot M^{-\frac{1}{2}} \cdot R^{-2} \cdot a_{s}^{\frac{7}{2}}
$$

then we can write

$$
\begin{aligned}
& J_{2}=-\frac{2\left(1-e^{2}\right)^{2}}{3 \cos I \cdot N_{0}}\left(\frac{a_{s}}{R}\right)^{2} \cdot \dot{\Omega}= \\
& =P \cdot G^{-\frac{1}{2}} \cdot M^{-\frac{1}{2}} \cdot R^{-2} \cdot a_{s}^{\frac{7}{2}} \cdot \dot{\Omega}=P \cdot K \cdot \dot{\Omega}
\end{aligned}
$$

and then - in the classical way of evaluating the $J_{2}$ variation is $\partial J_{2} / \partial t=\dot{J}_{2}=P \cdot K \cdot \ddot{\Omega}$ and also $\dot{C}_{20} / C_{20}=\dot{J}_{2} / J_{2}=\ddot{\Omega} / \dot{\Omega}$ finally holds.
While in (2.2) the parameter $P$ can be considered constant, the value of $K$ is affected at least by satellite altitude decay due to different types of drag - atmospheric drag, solar radiation drag, albedo, etc. - which are properly taken into account in the computations of $J_{2}$ variation that are commonly found in literature (Milani et al., 1987). It is evident in the above classic elaboration (2.1) and (2.2) that no possibility is envisaged for secular variation of $M, G$, and $R$ - all contained in $K$. But this is not the case if an expanding Earth with increasing mass and/or $G$ is assumed.

If the time variations of $G, M$, and $R$ are not neglected, it is easy to see that differentiating eq. (2.2), the expression for $\dot{J}_{2}$ can be written

$$
\begin{aligned}
& \dot{J}_{2}=P \cdot K \cdot \dot{\Omega} \cdot\left(\frac{\ddot{\Omega}}{\dot{\Omega}}-\frac{1}{2} \frac{\dot{G}}{G}-\frac{1}{2} \frac{\dot{M}}{M}-2 \frac{\dot{R}}{R}+\frac{7}{2} \frac{\dot{a}_{s}}{a_{s}}\right) \\
& \text { or } \frac{\dot{J}_{2}}{J_{2}}=\frac{\ddot{\Omega}}{\dot{\Omega}}-\frac{1}{2} \frac{\dot{G}}{G}-\frac{1}{2} \frac{\dot{M}}{M}-2 \frac{\dot{R}}{R}+\frac{7}{2} \frac{\dot{a}_{s}}{a_{s}}
\end{aligned}
$$

which can also be rearranged

$$
\frac{\ddot{\Omega}}{\dot{\Omega}}=\frac{\dot{J}_{2}}{J_{2}}+\frac{1}{2} \frac{\dot{G}}{G}+\frac{1}{2} \frac{\dot{M}}{M}+2 \frac{\dot{R}}{R}-\frac{7}{2} \frac{\dot{a}_{s}}{a_{s}} .
$$

From this last expression (2.3b) it is more clear that the astronomically observable quantity $\ddot{\Omega}$ is not determined only by $\dot{J}_{2} / J_{2}$ - apart from the satellite decay $\dot{a}_{s} / a_{s}$ - but it is also under the influence of variations of $G, M$ and $R$. Other factors can produce the total amount of $\ddot{\Omega}$ and then there exists the possibility that the value of $\dot{J}_{2} / J_{2}$ is in some amount incorrectly estimated because quotas of the observed $\ddot{\Omega}$ are not distributed to the other addends of the right side of (2.3b).

\section{Discussion}

Let us examine the typical values that can be assigned to $\ddot{\Omega} / \dot{\Omega}$ and to the five addends which appear in the righthand side of the expression (2.3b), listed in table I.

Now it can be considered:

i) Among the mechanical causes of the decreasing polar flatness of the Earth the isostatic glacial rebound is today considered a main 
cause, but recently some doubts have been raised - on geologic and geomorphologic basis - about the real cause of the uplift of the Fennoscandian Mountains (not due to deglaciation) (LidmarBergström et al., 2000).

ii) Different causes - linked to expanding Earth - can be envisaged on the origin of the Polar Motion (Scalera, 2002, 2003a,c, 2006). Polar Motion was formerly explained as being due to the deglaciation of an irregularly distributed ice cap (Peltier, 1976, 1981; Sabadini et al., 1982, 1983; Peltier and Jiang, 1996) (also this irregularity has been criticized: the main difficulty in this view is the estimation of the extensions and thickness of the paleo-icecap on Canadian and Siberian shields respectively. See Clark et al., 2001), but this phenomenon is incapable of explaining PM during the deep geological time (True Polar

Table I. Typical values that can be assigned to $\ddot{\Omega} / \dot{\Omega}$ and to the five addends which appear in the right hand side of the expression (2.3b).

\begin{tabular}{|c|c|c|c|}
\hline Kind & Quantity & Value & Comment \\
\hline Observed & $\ddot{\Omega} / \dot{\Omega}$ & $3.3 \cdot 10^{-8}$ & $\begin{array}{l}\text { If } \ddot{\Omega}=-15 \text { marcs } / \mathrm{yr}^{2} \text { (based on LLR modelling of UT1) } \\
\text { (other elaborations of observational data span from }-10 \\
\text { marcs } / \mathrm{yr}^{2} \text { by Rubincam to }-18 \text { marcs } / \mathrm{yr}^{2} \text { based on BIH } \\
\text { modelling of UT1; see Yoder } \text { et al., } 1983 \text { ). } \\
\text { Considering orbital parameters for Lageos: } \\
-\quad \text { Period }=3.758 \mathrm{~h} ; \\
-\quad \text { Semimajor axis }=a=12270 \mathrm{~km} ; \\
-\quad \text { Eccentricity }=e=0.004 ; \\
-\quad \text { Inclination }=I=109.94^{\circ} ; \\
-\quad \text { Equatorial Node Period }=1046 \text { days. }\end{array}$ \\
\hline Actual value & $J_{2}$ & 0.00108263 & \\
\hline Estimated value & $\dot{J}_{2}$ & $-2.8 \cdot 10^{-11}$ & Two order of magnitude higher than the expected value. \\
\hline Expected value & $\dot{J}_{2}$ & $-5.5 \cdot 10^{-13}$ & $\begin{array}{l}\text { Expected value taking into account only the decreasing } \\
\text { flatness due to the increasing LOD (Varga, 2002). }\end{array}$ \\
\hline Estimated value & $\dot{J}_{2} / J_{2}$ & $-2.6 \cdot 10^{-8}$ & \\
\hline Expected value & $\dot{J}_{2} / J_{2}$ & $-5.1 \cdot 10^{-10}$ & $\begin{array}{l}\text { Taking only the value coming from the slowing down } \\
\text { of the Earth spin. Neglecting the isostatic glacial } \\
\text { rebound contribution. }\end{array}$ \\
\hline Upper limit & $\dot{G} / G$ & $-10^{-9} \div-10^{-10}$ & $\begin{array}{l}\text { While precise orbital estimates provide a value of }-10^{-11} \\
\text { (Wesson, 1978; Müller, 1991), these estimates do not } \\
\text { consider the possibility of a variation of the involved } \\
\text { masses and consequent compensations in the searched } \\
\text { effects. }\end{array}$ \\
\hline Upper limit & $\dot{M} / M$ & $10^{-9}$ & $\begin{array}{l}\text { From geological records of heap of uncemented mater- } \\
\text { ials (Mann and Kanagy, 1990; Scalera, 2003b), and } \\
\text { from palaeogeography linked to secular polar motion } \\
\text { (Scalera, 2003a,c, 2006). }\end{array}$ \\
\hline Reasonable value & $\dot{R} / R$ & $0.8 \cdot 10^{-10}$ & $\begin{array}{l}\text { If } \dot{R}=0.5 \mathrm{~mm} / \mathrm{yr} \text { from considerations on an actual low } \\
\text { tectonic activity in the Recent, following the Map of } \\
\text { the spreading rates in the geologic time (Müller } \text { et al., } \\
\text { 1997; McElhinny and McFadden, 2000). }\end{array}$ \\
\hline Mean value & $\dot{R} / R$ & $2.4 \cdot 10^{-9}$ & $\begin{array}{l}\text { If } \dot{R}=1.5 \mathrm{~cm} / \mathrm{yr} \text { from palaeogeography on a geologic } \\
\text { time window of } 220 \text { Myr from Triassic to Recent } \\
\text { (Scalera, 2001, 2003c). }\end{array}$ \\
\hline Typical value & $\dot{a}_{s} / a_{s}$ & $-3.8 \cdot 10^{-8}$ & If $\dot{a}_{s}=-1.3 \mathrm{~mm} / \mathrm{day} \cong-47 \mathrm{~cm} / \mathrm{yr}$. \\
\hline
\end{tabular}


Wander lasts hundreds of Myr and cannot be sustained by a glacial rebound that lasts a few Myr or a fraction of a Myr).

iii) The absurd situation is that the same phenomenon, PM and TPW (TPW should be considered the prolongation of PM in the geological past), is explained today in two different ways, in the Recent as due to glacial rebound and before Recent attributed to the convective motions in the mantle.

Keeping in mind that the equalities I will write below cannot be perfect - because this is a first order analysis and serves only to make general considerations - I attempt heuristically to neglect completely the glacial rebound contribute with the aim to make evident other possible contributions to the anomalous high value of node deceleration, writing in (3.1b) only the expected value of the addend $\dot{J}_{2} / J_{2}$, and assigning arbitrarily a rate of radius increase of $0.5 \mathrm{~mm} / \mathrm{yr}$

$$
\begin{aligned}
& \frac{\ddot{\Omega}}{\dot{\Omega}}=\frac{\dot{J}_{2}}{J_{2}}+\frac{1}{2} \frac{\dot{G}}{G}+\frac{1}{2} \frac{\dot{M}}{M}+2 \frac{\dot{R}}{R}-\frac{7}{2} \frac{\dot{a}}{a} \\
& 3.3 \cdot 10^{-8}=\frac{\dot{J}_{2}}{J_{2}}-\frac{1}{2} \cdot 10^{-9}+\frac{1}{2} \cdot 10^{-9}+ \\
& +2 \cdot 0.8 \cdot 10^{-10}+\frac{7}{2} \cdot 3.8 \cdot 10^{-8}
\end{aligned}
$$

or, in the case of a rate of radius increase of 1.5 $\mathrm{cm} / \mathrm{yr}$ (the average rate determined by paleogeography on a Triassic-Recent time window; Scalera, 2001, 2003c)

$$
\begin{aligned}
& 3.3 \cdot 10^{-8}=\frac{\dot{J}_{2}}{J_{2}}-\frac{1}{2} \cdot 10^{-9}+\frac{1}{2} \cdot 10^{-9}+ \\
& +2 \cdot 2.4 \cdot 10^{-9}+\frac{7}{2} \cdot 3.8 \cdot 10^{-8} .
\end{aligned}
$$

From (3.1c) it is possible to become aware that the dominant term is the last one, the drag term, which produces an acceleration of the node, and that the $M$ and $R$ - if both increasing - reinforce this accelerating effect. It is to be noted that what is really observed is acceleration, because of the dominant effect of the spiralling of the satellites down to lower altitudes where the effect of the equatorial bulge is stronger. The observed value of the nodal deceleration has to be corrected by adding the term of acceleration coming from drag effects.

\section{Conclusions}

From the above considerations and from an examination of the magnitude orders of the quantities in (3.1b) and (3.1c) it can be concluded:

i) Only several centimetres of annual radius increase can have a non-negligible effect on the total of the summation (3.1a). Indeed, from the global palaeogeography, the mean rate on the geological time window Triassic-Recent, nearly $220 \mathrm{Myr}$, is $\cong 1.5 \mathrm{~cm} / \mathrm{yr}$ (Scalera, 2001, 2003c), and this value does not seem sufficient to have important effects on the (3.1a) balance, remaining the relative addendum one order of magnitude below the required $10^{-8}$. Due to the low rate of the present global tectonic activity (map of the oceans expansion rate in: Müller et al. 1997; McElhinny and McFadden, 2000) we should expect a rate in the Recent in the order of a few millimetres. Moreover the effect of an increasing radius can only be an increase of the velocity of the node (acceleration), while a deceleration is the reality. Consequently, a role of increasing radius in forming the observed value of the node deceleration can be excluded.

ii) The glacial rebound seems to be the real phenomenon capable of causing the ongoing higher than expected decreasing of the Earth's flatness, but additional contributions to $J_{2}$ variations, impossible at present to be separated, can come from the relaxation of the well known excess of equatorial bulge (Caputo, 1965, 1967; Alessandrini and Papi, 1987; Alessandrini, 1989), and from variations in the distribution of the Earth's waters - also underground water (Dickey et al., 1999; Rodell and Famiglietti, 1999; GRACE project).

iii) We can continue to consider Polar Motion (and True Polar Wander) and decreasing Earth's flatness as independent phenomena. Indeed both the following statements can hold: 1) PM-TPW can be driven - with a common explanation - by causes linked to an expansion of the Earth (Scalera, 2002, 2003c, 2006); 2) ice cap melting can easily explain the decreasing flatness of the Earth, but only using complicated modelling can it provide an explanation of PM - that however cannot be prolonged into the deep geological time to explain TPW. Thus polar ice caps melting is a suspicious explanation 
of PM because it produces a lack of unitary cause for clearly identical phenomena.

iv) Ice cap melting is also a suspicious cause of uplift of mountains because geological and geomorphological clues indicate different causes, eventually analogous to the causes of uplift of mountains at latitude far from the glacial circle parallel (Lidmar-Bergström et al., 2000; Ollier, 2006).

v) A decreasing $G$ gives an addend in ((3.1a) to (3.1c)) that can contribute only a minute term - in the order of $10^{-9}$ or less (Olive and Qian, 2004 ) - to the summation. The same holds for an increasing planetary mass, but with the same unfavourable trend (node acceleration instead of deceleration) as the increasing radius. Then $G$ and $M$ play an irrelevant role in this problem and an expansion of the Earth, whether due to inner changes of phases or to an increase in mass by an unknown cosmological process, cannot be distinguished by present artificial satellite technology.

vi) Finally, we may consider the improbable possibility that the increasing Earth radius could episodically reach a rate able to produce an acceleration of the node nearly equal to the mean deceleration - a situation of absence of deceleration really observed in the twenty-five years of data (1979-2003) in the four years time window 19972001 and still unexplained (Cazenave and Nerem, 2002; Cox and Chao, 2002). To produce a similar total compensation the radius time gradient should be of several $\mathrm{cm} / \mathrm{yr}$, which I think may be resolved without ambiguity from astrogeodetic global baseline measurement techniques (VLBI, GPS, ...). Moreover an episodic radius variation should not be compensated, as that concerns consequences on global angular moment, by deep Earth material ongoing differentiation, which is a different and independent process. Then we would have to expect a strong effect on LOD that has not been observed.

vii) The problem of the difficulty in separating the global expansion, with its effect of an increasing radius on the equator, and the glacial isostatic rebound and/or relaxation of the $\cong 100 \mathrm{~m}$ excess of equatorial bulge (Caputo, 1965, 1967; Alessandrini and Papi, 1987; Alessandrini, 1989) with their effect of a decreasing equatorial radius, is still open (Scalera, 2003c). viii) The problem of a precise separation of the drag driven orbital decay from the global uplift of the Earth surface (global expansion) is not resolvable at present. The annual rate of radius increase is only from 1/10 (a few centimetres, too optimistic) to $1 / 100$ (a few millimetres, more realistic) of the annual orbit decay (several tens of centimetres). Thus variation of the radius, of $G$ and of $M$ can be easily contained in the decay as a small additional unrecognized term. The only way to detect the non-classic parameters variation rate in the satellites' orbits is to eliminate all sources of drag. In this light, the new experimental development of GRAVITY PROBE B (Anonymous, 2005), which - besides the investigation of minute relativistic effects may be the first example of an orbiting mass shielded from the causes of drag, promising to open a new epoch in global positioning satellite geodesy.

\section{Acknowledgements}

My gratitude and thanks to Dr. Matt Edwards and Prof. Michele Caputo, who provided invaluable suggestions for the improvement of this short note.

\section{REFERENCES}

AlessandRINI, B. (1989): The hydrostatic equilibrium figure of the Earth: an iterative approach, PEPI, 54, 180-192.

Alessandrini, B. and G.M. PAPI (1987): The shape of a planet in hydrostatic equilibrium: an application to the Earth, Nuovo Cimento, 10C (4), 349-363.

AnONymous (2005): Gravity Probe B - Testing Einstein's Universe, NASA Facts, February 2005, 1-6.

BeEkMAN, G. (2006): I.O. Yarkovsky and the discovery of 'his' effect, J. Hist. Astron., XXXVII, 71-86.

Caputo, M. (1965): The minimum strenght of the Earth. J. Geophys. Res., 70 (4), 955-963.

CAPuto, M. (1967): The gravity field of the Earth (Academic Press, New York), pp. 198.

CAZENAVE, A. and R.S. NerEm (2002): Redistributing Earth's mass, Science, 297, 783-784.

Clark, P.U., A.C. Mix and E. Bard (2001): Ice sheets and sea level of the last glacial maximum, Eos, Trans. Am. Geophys. Un., 82 (22), 241-247.

Cox, C.M. and B.F. CHAO, (2002): Detection of a largescale mass redistribution in the Terrestrial system since 1998, Science, 297, 831-833.

Dickey, J.O., C. Bentley, R. Bilham, J.A. Carton, R.J. EANes, T.A. Herring, W.A. KaUla, G.S.E. LAGER- 
LOEF, S. Rojstaczer, W.H.F. Smith, H.M. VAN DEN DOOL, J.M. WAHER and M.T. ZUBER (1999): Gravity and hydrosphere: new frontier, Hydrol. Sci. J., 44 (3) 407-415.

Edwards, M.R. (Editor) (2002): Pushing Gravity - New Perspectives on Le Sage's Theory of Gravitation (Apeiron - C. Roy Keys Inc., Montreal, Canada), pp. 316.

HilgenberG, O.C. (1929): Das Rätsel Gravitation gelöst (Solution to the Mystery of Gravitation) (Kassel), pp. 14.

HiLgenBerG, O.C. (1931): Über Gravitation, Tromben und Wellen in bewegten Medien (On Gravitation, Vortices and Waves in Moving Bodies), (Berlin), pp. 78.

HilgenBerG, O.C. (1933): Vom wachsenden Erdball (The Expanding Earth) (Giessmann \& Bartsch, Berlin), pp. 56.

KaUla, W.M. (1966): Theory of Satellite Geodesy - Applications of Satellites to Geodesy (Braisdell Publ. Company, Waltham, reprinted by Dover Publ. Inc. 2000), pp. 124.

KaULA, W.M. (1983): The changing shape of the Earth, $\mathrm{Na}$ ture, 303, 756-756.

Lidmar-Bergström, K., C.D. Ollier and J.R. Sulebak (2000): Landforms and uplift history of Southern Norway, Global Planet. Change, 24, 211-231.

Mann, C.J. and S.P. Kanagy (1990): Angles of repose that exceed modern angles, Geology, 18, 358-361.

McElhinny, M.W. and P.L. McFAdDEn (2000): Paleomagnetism, continents and oceans (Academic Press, New York), pp. 380.

Milani, A., A.M. Nobili and P. FARINElla (1987): Non-gravitational Perturbations and Satellite Geodesy (Adam Hilger, Bristol), pp. 125.

MüLleR, J. (1991): Analyse von Lasermessungen zum Mond im Rahmen einer post-Newton'schen Theorie - Dissertationen (Deutsche Geodätische Kommission, München), pp. 132.

MÜller, R.D., W.R. RoEst, J.Y. RoYeR, L.M. GAHAGAN and J.G. SCLATER (1997): Digital isochrons of the world's ocean floor, J. Geophys. Res., 102, 3211-3214.

Olive, K.A. and Y.-Z. QIAN (2004): Were fundamental constants different in the past?, Physics Today, 57 (10), 40-45.

OlLIER, C. (2006): Mountain uplift, climate and isostasy, New Concepts in Global Tectonics Newsletter, 40, 14-17.

PeltiER, W.R. (1976): Glacial isostatic adjustment, 2. The inverse problem, Geophys. J. R. Astron. Soc., 46, 669-705.

Peltier, W.R. (1981): Ice age geodynamics, Ann.Rev. Earth Planet. Sci., 9, 199-225.

Peltier,W.R. and X. JiAng (1996): Glacial isostatic adjustment and Earth rotation: refined constraints on the viscosity of the deepest mantle, J. Geophys. Res., 101, 3269-3290.

Rodell, M. and J.S. FAmiglietti (1999): Detectability of variations in continental water storage from satellite observations of the time dependent gravity field, Water Resour. Res., 35 (9), 2705-2723.

SABADINI, R., D.A.YuEN and E. BoschI (1982): Polar wandering and the forced responses of a rotating, multilayered, viscoelastic planet, J. Geophys. Res., 87, 2885-2903.

SABAdini, R., D.A. Yuen and E. Boschi (1983): Dynamic effects from mantle phase transitions on true polar wander during ice ages, Nature, 303, 694-696.

SCALERA, G. (1993a): A model of the evolution of the trench- arc-backarc zones without subduction, Eos, Trans., Am. Geophys. Un., 74 (43), 647.

ScAlera, G. (1993b): Non-chaotic emplacements of trench-arc zones in the Pacific Hemisphere, Ann. Geofis., XXXVI (5-6), 47-53.

ScAlERA, G. (1994): Earth Complexity versus Plate Tectonic Simplicity, in Frontiers of Fundamental Physics edited by M. BARONE and F. SELleri (Plenum Press, New York), 257-273.

SCALERA, G. (1997): The relation among seismic activity, volcanic rock emplacement and Bouguer anomalies in Italy, Natural Hazards, 15, 165-181.

SCALERA, G. (1998): Paleogeographical reconstructions compatible with Earth dilatation. Ann. Geofis., 41 (5-6), 819825

ScAlERA, G. (2001): The Global paleogeographical reconstruction of the Triassic in the Earth's dilatation framework and the paleoposition of India, Ann. Geofis., 44 (1), 13-32.

SCAlERA, G. (2002): Possible relations among expanding Earth, TPW and Polar Motion, in Proceedings International Symposium on New Concepts in Global Tectonics, edited by L. MasLov, May 2002, La Junta, Colorado (Otero Junior College Press, La Junta), 37-50.

SCALERA, G. (2003a): Relations among expanding Earth, TPW and Polar Motion, in Atti del $20^{\circ}$ Convegno Nazionale GNGTS (Proceedings 20th National Meeting of the National Group Geophysics of Solid Earth) edited by D. SlejKo, 6-8 November 2001, Roma, (CNR-OGS, Roma), (on CD-ROM).

ScAlerA, G. (2003b): Gravity and expanding Earth, in Atti del $20^{\circ}$ Convegno Nazionale GNGTS (Proceedings 20th National Meeting of the National Group Geophysics of Solid Earth) edited by D. SLEJKO, 6-8 November 2001, Rome, (CNR-OGS, Roma), (on CD-ROM).

SCALERA, G. (2003c): The expanding Earth: a sound idea for the new millennium, in 'Why Expanding Earth? A book in Honour of Ott Christoph Hilgenberg', Proceedings of the 3rd Lautenthaler Montanistisches Colloquium, edited by G. SCALERA and K.-H. JACOB, Mining Industry Museum, Lautenthal (Germany), May 26, 2001, (INGV, Rome), 181-232.

ScAlerA, G. (2006): TPW and Polar motion as due to an asymmetrical Earth expansion, Ann. Geophysics, 49 (suppl. to no. 1), 483-500.

VArGa, P. (2002): Geophysical Geodesy Beyond 2000, in Quo vadis geodesia ...?, edited by F. KRUMM and V.S. Schwarze, Tech. Rep. Dep. Geodesy Geoinf. No.199 (University of Stuttgart, Germany), 487-496.

Wesson, P.S. (1978): Cosmology and Geophysics (Hilger/ Oxford University Press, New York), pp. 240.

Yoder, C.F., J.G. Williams, J.O. Dickey, B.E. SchutZ, R.J. EANES and B.D. TAPLEY (1983): Secular variation of Earth's gravitational harmonic $J_{2}$ coefficient from Lageos and nontidal acceleration of the Earth rotation, Nature, 303, 757-762.

YARKOVSKI, J. (1888): Hypotèse cinétique de la gravitation universelle en connexion avec la formation des éléments chimiques (Kinetic hypothesis of the universal gravitation and its connection with the formation of chemical elements), (Chez l'Auteur, Moscou), pp.139 (in French). 